\title{
Cerebroplacental Ratio in Non Small for Gestational Age Fetuses at 28 to 38 Weeks of Gestation
}

\author{
Yalda Jefride ${ }^{1}$, Mojgan Barati ${ }^{1}$, Kobra Shojaei ${ }^{1}$, Sareh Aberoumand ${ }^{1 *}$, Sara Masihi ${ }^{1}$, Mohamad \\ Momengaribvand ${ }^{2}$
}

\begin{abstract}
Objectives: Cerebroplacental ratio (CPR) is a useful tool in differentiating at-risk non-SGA fetuses. The first CPR reported by Arbeille et al quantifies the redistribution of the cardiac output. In this study, we investigate CPR in non-SGA fetuses.

Materials and Methods: This descriptive-analytic study was carried out in Ahvaz from January 1, 2016 to January 1, 2017. In this study, CPR was evaluated in 230 pregnant women at 28 to 38 weeks of gestation, with the exception of pregnant women with SGA and multiple pregnancies. In this study, factors such as maternal age, parity (nullipara and multipara), history of abortion, cesarean delivery or vaginal delivery, an estimate of fetal weight (EFW), history of stillbirth, pregnancy conceived through assisted reproductive technology, and NT values were investigated.

Results: In this study, of 230 pregnant women with an EFW more than the 3rd percentile and singleton pregnancy, there were 22 women with a CPR below the 5th centile. There was no relationship between the fetal CPR and the maternal age, the number of maternal cesarean section, the number of mother's vaginal deliveries and the parity, history of stillbirth, pregnancy conceived through assisted reproductive technology and NT values in the data analyzed.

Conclusions: In this study, 9.6\% of the non-SGA fetuses had abnormal CPR (less than 5 percentile). There is no relationship between $\mathrm{CPR}$ and maternal age, parity (nullipara and multipara), history of abortion, cesarean section delivery or vaginal delivery, EFW, history of stillbirth, pregnancy conceived through assisted reproductive technology, and NT values.

Keywords: Cerebroplacental ratio, Parity, Abortion, Vaginal delivery, Estimate of fetal weight, Nuchal translucency, Doppler study
\end{abstract}

\section{Introduction}

Pregnancy and labor are great experiences in the life of a woman. At the end of the 20 th century, the mortality ratio of infants has fallen from more than $90 \%$ to $7.2 \%$ per live birth (1). Studies have shown that a death rate of 1.2-1.3 can be prevented in fetuses and neonates(2). Today, the diagnosis of high-risk pregnancies is one of the important issues in the field of modern pregnancy and labor. Fetal growth during pregnancy is determined by its anthropometric measures, especially the weight. In fact, the birth weight of a baby is the most important determinant of disease or death (3). A low birth weight baby is considered as a baby with a weight less than $2500 \mathrm{~g}$ at birth. These infants are 40 times more likely to be exposed to neonatal mortality than normal babies, who have a birth weight of more than $2500 \mathrm{~g}$ (4). Low birth weight babies are divided into 2 groups as follows: The first group includes premature infants who do not have enough gestational time to develop and grow. The second group includes termed infants, that is, the babies whose gestational age is 37 weeks or more. These babies, despite having enough time to grow, are very small at birth and have a birth weight less than $2500 \mathrm{~g}$ (5). Intrauterine growth restriction (IUGR) is a significant part of the present mortality. The primary goal of the prenatal care is to diagnose conditions and to choose the appropriate and optimal treatment for the mother and the fetus. The management of complicated pregnancies from IUGR remains a major challenge in maternity and childbirth. The complications of IUGR are remarkable for the mother and the fetus (6-11). Babies with birth weights less than the 10th percentile of weight for the gestational age, according to the sex are called the IUGR $(12,13)$. Ultrasound Doppler sonography is a supplement to the diagnosis of physiological disorders (14). Color Doppler sonography of the fetal brain is used to investigate the incidence of uterine growth retardation, fetal distress, asphyxia, anemia, pregnancy immunization, twin to twin transfusion syndrome (TTTS), and the examination of the middle cerebral artery, usually without regard to its various parts. Uterine placental blood flow can be detected by Doppler sonography, a non-invasive method. This ultrasound is very important in a high-risk pregnancy. The umbilical Doppler is considered as one of the methods for assessing fetoplacental blood flow, so cord blood flow can be considered as a predictor of high-risk pregnancies without any unnecessary invasive interventions of midwifery. It has also led to a reduction of multiple complications, including perinatal mortalities, 
hospital admissions, hospitalization duration, labor induction and cesarean section, fetal distress during labor, and hypoxic encephalopathy $(15,16)$.

Cerebroplacental ratio (CPR) is a new good tool for differentiating the at-risk non-SGA fetuses. The first CPR reported by Arbeille et al quantifies the redistribution of the cardiac output $(17,18)$. According to the brain sparing theory, in any form of fetal distress, it can be seen that a decrease in the blood flow to the fetus leads to a decrease in the resistance of the cerebral arteries to prevent the blood supply to the brain. This change is seen as an increase in the end-diastolic velocity (EDV). Several studies were performed with the help of Doppler velocity measurements of uterine arteries in the second trimester to predict the complications of preeclampsia on the fetus in high-risk pregnancies $(19,20)$. A cerebroplacental Doppler ratio, defined as the ratio of the umbilical artery PI to the MCA PI, is an important predictor of adverse outcomes during pregnancy, and this includes implications for the proper evaluation of the SGA and AGA fetuses. As mentioned before, CPR is obtained by dividing the Doppler indices of the middle cerebral artery (MCA) by the indices of umbilical cord vessels. When these changes occur, diastolic flow increases in the MCA (21-30).

The main aim of this study was to investigate CPR in non-SGA fetuses at 28 to 38 weeks of gestation.

\section{Materials and Methods}

This descriptive-analytic study was conducted in Ahvaz in 2016. The sample consists of 230 pregnant women referred to the Prenatal Clinic of Imam Hospital. This study was performed from January 1, 2016 until January 1, 2017. All women at 28 to 38 weeks of gestation, without SGA and multiple pregnancies, with a Doppler scan (umbilical PI, MCA PI, and CPR), and a growth scan in these weeks, were included. In this study, factors such as maternal age, parity (Nullipara and Multipara), history of abortion, cesarean delivery or vaginal delivery and estimate of fetal weight (EFW), history of stillbirth, pregnancy conceived through assisted reproductive technology, and NT values were investigated separately. Growth and Doppler scans were done by a certified sonographer in the prenatal clinic of Imam Hospital in Ahvaz. The ultrasound devices used in this study were Medison V10 and V20. Data were entered into Astraia software. CPR below the 5th percentile was described as abnormal. CPR was divided into 2 groups of 2.5-5 and below 2.5 .

\section{Results}

According to Table 1 and Figure 1, 208 (90.4\%), 17 (7.4\%), and 5 women $(2.2 \%)$ had a CPR greater than $5,2.5-5$, and less than 2.5 , respectively. In this way, 22 of the studied patients had a CPR less than $5(9.6 \%)$, which is considered as an abnormal condition during pregnancy and should be taken into consideration. In fact, $9.6 \%$ of the samples are in this range. The following table is designed to determine the relationship between the weight percentile of the sample (22 cases) and the CPR. CPR is $9.6 \%$ according to Table 2 and Figure 2. It was revealed that these 22 cases with CPR less than $5 \%$ of the weight percentile are normally distributed and that high or low frequency does not belong to a certain percentile. Therefore, according to this analysis, it can be concluded that in the present study, CPR less than 5 can occur per weight percentile.

The subjects' mean age was 29.8 years. Out of 230 persons, 59 people had an abortion $(25.7 \%)$, of which 39 people (17\%) have had one miscarriage and 16 cases (9\%) had more than one miscarriage. In addition, 119

Table 1. Frequency of CPR Variables in the Samples

\begin{tabular}{llll}
\hline CPR & No. & $\%$ & Cumulative Percentage \\
\hline$>5$ & 208 & 90.4 & 90.4 \\
$<5$ and $>2.5$ & 17 & 7.4 & 97.8 \\
$<2.5$ & 5 & 2.2 & 100.0 \\
Total & 230 & 100.0 & \\
\hline
\end{tabular}

Abbreviation: CPR, cerebroplacental ratio.

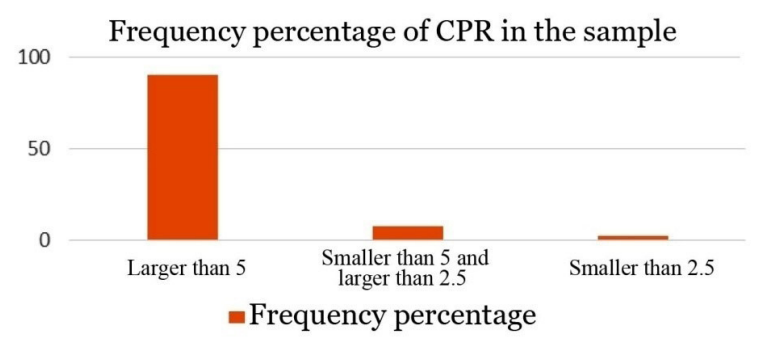

Figure 1. Frequency Percentage of Cerebroplacental Ratio in the Samples.

Table 2. CPR Versus Weight Percentile (in Subjects With CPR $<5)$

\begin{tabular}{lcccccc}
\hline \multirow{2}{*}{ CPR } & \multicolumn{5}{c}{ EFW $^{* * *}$} \\
\cline { 2 - 6 } & $\mathbf{3 - 1 0}$ & $\mathbf{1 0 - 2 5}$ & $\mathbf{2 5 - 5 0}$ & $\mathbf{5 0 - 7 5}$ & $\mathbf{7 5 - 9 5}$ & Total \\
\hline$>2.5,<5$ & 1 & 5 & 7 & 3 & 1 & 17 \\
$<2.5$ & 0 & 1 & 3 & 1 & 0 & 5 \\
Total & 1 & 6 & 10 & 4 & 1 & 22 \\
\hline
\end{tabular}

Abbreviation: CPR, cerebroplacental ratio; EFW, Estimate of fetal weight.

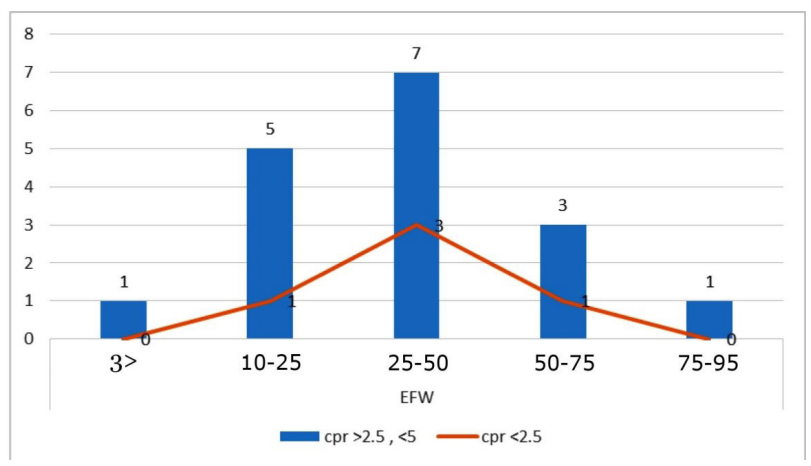

Figure 2. A Chart of Cerebroplacental Ratio Versus Weight Percentile (for People With Cerebroplacental Ratio <5). 
women had no previous history of delivery, and 111 have experienced childbirth and were divided in the way described below. Two of the subjects had both a normal delivery and a cesarean section, 81 had a cesarean section during their first pregnancy, 6 had cesarean sections in both of their pregnancies, and 3 had a cesarean section in each of their three pregnancies. Furthermore, 17 people had a normal delivery in the first pregnancy, 2 in both cases of normal pregnancy, 1 in each of the three pregnancies had a normal delivery. Thus, out of these 111 people, 19 had only normal delivery, 90 had only cesarean section, and 2 had both cesarean and normal delivery. The average fetal weight by ultrasound was $1900 \mathrm{~g}$. The highest frequency (95) was related to the 25th-50th percentile, and the lowest frequency (7) belonged to the 3rd-10th percentile. The mean value of NT in this study was 1.7440 .

\section{Discussion}

In this study, 9.6\% of non-SGA fetuses had abnormal CPR (less than 5 percentile). There is no relationship between CPR and maternal age, parity (Nullipara and multipara), history of abortion, cesarean section delivery or vaginal delivery, EFW, history of stillbirth, pregnancy conceived through assisted reproductive technology, and NT values. In a study, Akolekar et al used the CPR in the third trimester of pregnancy to predict the results of SGA pregnancy and prevent the death of fetuses and early delivery (31). Odibo et al conducted a study in 2005 and found that the CPR and its adverse effects limited intrauterine growth (32). Khalil et al (28) showed that CPR was more associated with placental abnormalities than the fetal weight which was in contrast with the results found by Achan and Anti. Morales-Rosello and Khalil showed that fetal smallness is largely due to placental insufficiency and fetuses with a normal weight and a low CPR may have chronic hypoxia; so they are recommended to evaluate a hybrid approach of EFW (the weight of the fetal ultrasound) and CPR. In their research, CPR (uterine artery Doppler), along with EFW during the third trimester of pregnancy, was able to identify deliveries that could lead to the loss of a baby or high-risk childbirth (33).

In a study on the relationship between $\mathrm{CPR}$ and birth weight in the macrosomic fetus, Abdella et al showed that CPR cannot distinguish between the AGA and LGA fetuses (34). Khalil and Thilaganathan showed that a combination of the estimation of the fetal weight, CPR, and uterine Doppler in the third trimester could identify most of the at-risk fetus for the birth of a dead baby (35). Regarding the results of this study, it was observed that there is no significant relationship between cerebral blood flow in the fetus brain and body weight percentile in this study and this lack of association suggests that CPR cannot be a good predictor for the differentiation between the LGA, SGA and AGA fetuses. This means that low CPR is not specific to the percentile of low weights. The results of this research are different from those of the studies conducted by Akolekar et al (31) and Odibo et al (32) are in line with the views of Khalil et al (28), Morales-Rosello and Khalil (33), Abdella et al (34), and Khalil et al (35).

\section{Conclusions}

In the studies conducted, considering that parameters such as maternal age, parity (nullipara and multipara), abortion history, cesarean section delivery or vaginal delivery, history of stillbirth, pregnancy conceived through assisted reproductive technology, and NT values are important, the effects of these parameters on the CPR were investigated and the following results were obtained. There is no relationship between the blood flow to the brain in the fetus and the mother's age, the number of cesarean section, the number of normal mother deliveries, the parity, history of stillbirth and abortion, pregnancy conceived through assisted reproductive technology, and NT values.

\section{Conflict of Interests}

Authors declare that they have no conflict of interests.

\section{Ethical Issues}

This paper was extracted from the corresponding author's thesis for a specialist degree in Obstetrics and Gynecology which was approved by the Ethics Committee of Ahvaz Jundishapur University of Medical Sciences (IR.AJUMS. REC.1396.454).

\section{Financial Support}

The research has been financially supported by Ahvaz Jundishapur University of Medical Sciences.

\section{Acknowledgments}

Hereby, assistance and cooperation of research deputy of Ahvaz Jundishapur University of Medical Science and the participants are appreciated.

\section{References}

1. Cunningham FG, Leveno KJ, Bloom SL, Hauth JC, Gilstrap LC, Wenstrom KD. Williams obstetrics. 22nd ed. New York: Mc Grow-Hill; 2005.

2. Partodel M. Summery obstetrics \& gynecology. Tehran: Yad; 1994:14-15.

3. Rondo PH, Tomkins AM. Chest circumference as an indicator of intrauterine growth retardation. Early Hum Dev. 1996;44(3):161-167.

4. Bosetti, C M.J, Nieuwenhuijsen S, Gallus S, Cipriani C, La Vecchia, F Parazzini. Ambient particulate matter and preterm birth or birth weight: A review of the literature. Arch Toxicol. 2010; 84:447-460.

5. Durousseau S, Chavez GF. Associations of intrauterine growth restriction among term infants and maternal pregnancy intendedness, initial happiness about being pregnant, and sense of control. Pediatrics. 2003;111(5 Pt 2):1171-1175.

6. Unterscheider J, O’Donoghue K, Daly S, et al. Fetal 
growth restriction and the risk of perinatal mortalitycase studies from the multicentre PORTO study. BMC Pregnancy Childbirth. 2014;14:63. doi:10.1186/14712393-14-63

7. Cruz-Martinez R, Figueras F, Hernandez-Andrade E, Oros D, Gratacos E. Fetal brain Doppler to predict cesarean delivery for nonreassuring fetal status in term small-for-gestational-age fetuses. Obstet Gynecol. 2011;117(3):618-626. doi:10.1097/ AOG.0b013e31820b0884

8. Crispi F, Figueras F, Cruz-Lemini M, Bartrons J, Bijnens B, Gratacos E. Cardiovascular programming in children born small for gestational age and relationship with prenatal signs of severity. Am J Obstet Gynecol. 2012;207(2):121.e121-129. doi:10.1016/j. ajog.2012.05.011

9. Meher S, Hernandez-Andrade E, Basheer SN, Lees C. Impact of cerebral redistribution on neurodevelopmental outcome in small-for-gestational-age or growthrestricted babies: a systematic review. Ultrasound Obstet Gynecol. 2015;46(4):398-404. doi:10.1002/uog.14818

10. Prior T, Paramasivam G, Bennett P, Kumar S. Are fetuses that fail to achieve their growth potential at increased risk of intrapartum compromise? Ultrasound Obstet Gynecol. 2015;46(4):460-464. doi:10.1002/uog.14758

11. Baschat AA, Cosmi E, Bilardo CM, et al. Predictors of neonatal outcome in early-onset placental dysfunction. Obstet Gynecol. 2007;109(2 Pt 1):253-261. doi:10.1097/01.aog.0000253215.79121.75

12. Chauhan SP, Beydoun H, Chang E, et al. Prenatal detection of fetal growth restriction in newborns classified as small for gestational age: correlates and risk of neonatal morbidity. Am J Perinatol. 2014;31(3):187194. doi:10.1055/s-0033-1343771

13. Coria-soto IL, Bobadilla JL, Notzon F. The effectiveness of antenatal care in preventing intrauterine growth retardation and low birth weight due to preterm delivery. Int J Qual Health Care. 1996;8(1):13-20.

14. Parra M, Rodrigo R, Barja $\mathrm{P}$, et al. Screening test for preeclampsia through assessment of uteroplacental blood flow and biochemical markers of oxidative stress and endothelial dysfunction. Am J Obstet Gynecol. 2005;193(4):1486-1491. doi:10.1016/j.ajog.2005.02.109

15. Cunningham $G$, Leveno $K$, Bloom $S$, Hauth JC. Chronic hypertension. In: Cunningham G, ed. Williams Obstetrics. 22nd ed. USA, Philadelphia: McGraw-Hill; 2005:1044.

16. Mari G, Hanif F. Fetal Doppler: umbilical artery, middle cerebral artery, and venous system. Semin Perinatol. 2008;32(4):253-257. doi:10.1053/j.semperi.2008.04.007

17. Arbeille P, Roncin A, Berson M, Patat F, Pourcelot L. Exploration of the fetal cerebral blood flow by duplex Doppler--linear array system in normal and pathological pregnancies. Ultrasound Med Biol. 1987;13(6):329-337.

18. Arbeille P, Maulik D, Fignon A, et al. Assessment of the fetal PO2 changes by cerebral and umbilical Doppler on lamb fetuses during acute hypoxia. Ultrasound Med Biol. 1995;21(7):861-870.

19. Arduini D, Rizzo G, Romanini C, Mancuso S. Uteroplacental blood flow velocity waveforms as predictors of pregnancy-induced hypertension. Eur J Obstet Gynecol Reprod Biol. 1987;26(4):335-341.

20. Trudinger BJ, Giles WB, Cook CM. Flow velocity waveforms in the maternal uteroplacental and fetal umbilical placental circulations. Am J Obstet Gynecol. 1985;152(2):155-163.

21. Arbeille P, Body G, Saliba E, et al. Fetal cerebral circulation assessment by Doppler ultrasound in normal and pathological pregnancies. Eur J Obstet Gynecol Reprod Biol. 1988;29(4):261-273.

22. Ebbing C, Rasmussen S, Kiserud T. Middle cerebral artery blood flow velocities and pulsatility index and the cerebroplacental pulsatility ratio: longitudinal reference ranges and terms for serial measurements. Ultrasound Obstet Gynecol. 2007;30(3):287-296. doi:10.1002/ uog. 4088

23. Morales-Rosello J, Khalil A, Morlando M, Papageorghiou A, Bhide A, Thilaganathan B. Changes in fetal Doppler indices as a marker of failure to reach growth potential at term. Ultrasound Obstet Gynecol. 2014;43(3):303-310. doi:10.1002/uog.13319

24. Mula R, Savchev S, Parra M, et al. Increased fetal brain perfusion and neonatal neurobehavioral performance in normally grown fetuses. Fetal Diagn Ther. 2013;33(3):182-188. doi:10.1159/000350699

25. Jugovic D, Tumbri J, Medic M, et al. New Doppler index for prediction of perinatal brain damage in growthrestricted and hypoxic fetuses. Ultrasound Obstet Gynecol. 2007;30(3):303-311. doi:10.1002/uog.4094

26. Roza SJ, Steegers EA, Verburg BO, et al. What is spared by fetal brain-sparing? Fetal circulatory redistribution and behavioral problems in the general population. Am J Epidemiol. 2008;168(10):1145-1152. doi:10.1093/aje/ kwn233

27. Khalil AA, Morales-Rosello J, Elsaddig M, et al. The association between fetal Doppler and admission to neonatal unit at term. Am J Obstet Gynecol. 2015;213(1):57.e51-57. doi:10.1016/j.ajog.2014.10.013

28. Khalil AA, Morales-Rosello J, Morlando M, et al. Is fetal cerebroplacental ratio an independent predictor of intrapartum fetal compromise and neonatal unit admission? Am J Obstet Gynecol. 2015;213(1):54.e5110. doi:10.1016/j.ajog.2014.10.024

29. Devine PA, Bracero LA, Lysikiewicz A, Evans R, Womack S, Byrne DW. Middle cerebral to umbilical artery Doppler ratio in post-date pregnancies. Obstet Gynecol. 1994;84(5):856-860.

30. Figueras F, Lanna M, Palacio M, et al. Middle cerebral artery Doppler indices at different sites: prediction of umbilical cord gases in prolonged pregnancies. Ultrasound Obstet Gynecol. 2004;24(5):529-533. doi:10.1002/uog.1738

31. Akolekar R, Syngelaki A, Gallo DM, Poon LC, Nicolaides KH. Umbilical and fetal middle cerebral artery Doppler at 35-37 weeks' gestation in the prediction of adverse perinatal outcome. Ultrasound Obstet Gynecol. 2015;46(1):82-92. doi:10.1002/uog.14842

32. Odibo AO, Riddick C, Pare E, Stamilio DM, Macones GA. Cerebroplacental Doppler ratio and adverse perinatal outcomes in intrauterine growth restriction: 
evaluating the impact of using gestational age-specific reference values. J Ultrasound Med. 2005;24(9):12231228.

33. Morales-Rosello J, Khalil A. Fetal cerebral redistribution: a marker of compromise regardless of fetal size. Ultrasound Obstet Gynecol. 2015;46(4):385-388. doi:10.1002/uog.15664

34. Abdella RMA, Ahmed SAM, Moustafa MI. Sonographic evaluation of fetal abdominal circumference and cerebroplacental Doppler indices for the prediction of fetal macrosomia in full term pregnant women. Cohort study. Middle East Fertil Soc J. 2014;19(1):69-74. doi:10.1016/j.mefs.2013.04.008

35. Khalil A, Thilaganathan B. Role of uteroplacental and fetal Doppler in identifying fetal growth restriction at term. Best Pract Res Clin Obstet Gynaecol. 2017;38:3847. doi:10.1016/j.bpobgyn.2016.09.003

(c) 2018 The Author (s); This is an open-access article distributed under the terms of the Creative Commons Attribution License (http://creativecommons.org/licenses/by/4.0), which permits unrestricted use, distribution, and reproduction in any medium, provided the original work is properly cited. 